\title{
Psycho-social factors associated with premature ejaculation among the patients attending in a tertiary level psychiatric hospital, Dhaka, Bangladesh
}

\author{
Saifun Nahar, ${ }^{1}$ Md Mazharul Shaheen, ${ }^{2}$ Towhidul Islam, ${ }^{3}$ SM Abu Hena Mostafa Alim, ${ }^{4}$ Md Faruq Alam ${ }^{5}$ \\ ${ }^{1}$ Assistant Professor, Department of Psychiatry, National Institute of Mental Health (NIMH), Sher-E-Bangla Nagar, Dhaka, Bangladesh; \\ ${ }^{2}$ Associate Professor, Department of ENT and Head-Neck Surgery, Sheikh Sayera Khatun Medical College, Gopalganj, Bangladesh; \\ ${ }^{3}$ Assistant Registrar, Department of Psychiatry, Sir Salimullah Medical College and Mitford Hospital, Dhaka, Bangladesh; ${ }^{4}$ Assistant \\ Professor, Department of Psychiatry, Rajshahi Medical College, Rajshahi, Bangladesh; ${ }^{5}$ Professor, Department of Child, Adolescents \\ and Family Psychiatry, NIMH, Sher-E-Bangla Nagar, Dhaka, Bangladesh.
}

$\begin{array}{ll}\text { Article info } & \\ \text { Received } & : \text { 16 July, 2018 } \\ \text { Accepted } & : 25 \text { Aug. } 2018 \\ \text { Number of tables } & : 02 \\ \text { Number of figures } & : 01 \\ \text { Number of refs } & : 27\end{array}$

\section{Correspondence}

Saifun Nahar

Mobile: +8801712119277

Email: saifunsumi@gmail.com

\begin{abstract}
Summary
Premature ejaculation (PE) has been considered as the most common male sexual dysfunction affecting men and their partners. The objective of the study was to find out the proportion of $\mathrm{PE}$, associated psycho-social factors and psychiatric co- morbidities among the patients attended in the Sexual Dysfunction Clinic of National Institute of Mental Health, Dhaka, Bangladesh. This was a cross-sectional study conducted from August 2017 to June 2018. For this purpose 280 male patients with complaints of sexual dysfunction aged from 18 to 60 years were selected by convenient sampling technique. A semi-structured, self-administered questionnaire containing socio-demographic variables, Bangla version of the premature ejaculation diagnostic tool (PEDT), Bangla version of the depression anxiety stress scales (DASS 21-BV) were applied to assess their $\mathrm{PE}$ and associated depression, anxiety and stress respectively. The results showed that, mean (+SD) age of the respondents was $38.8(+8.44)$ years and $26.4 \%$ of the respondents were found to have PE. Presence of PE was slightly higher (55.4\%) among the older age group (aged 41-60 years) than the younger age group (aged 18-40 years). Chi-square test showed significant association with religion, smoking status and psychiatric co-morbidities with presence of $\mathrm{PE}$ ( $\mathrm{p}<0.05$ for all comparisons). This high prevalence and associated psychosocial factors illustrate the need for promoting awareness and development of standardized methods for diagnosis, assessment and treatment of PE.
\end{abstract}

Bang J Psychiatry 2017;31(2): 27-31

\section{Introduction}

Premature ejaculation (PE) is found as a common male sexual dysfunction in different large population based surveys. ${ }^{1-3}$ All through history, PE has been defined in many ways by several professional organizations and individuals. ${ }^{4-6}$ With the varying definitions of PE the prevalence of PE differs. On average, most studies reported a prevalence ranging from $20 \%$ to $31.6 \% .^{7-12}$

The Diagnostic and Statistical Manual of Mental Disorders (DSM), edition- IV (Text Revision) by the American Psychiatric Association (APA) defines PE as persistent or recurrent ejaculation with minimal sexual stimulation before, on, or shortly after penetration and before the person wishes it, with the disturbance causing marked distress or interpersonal difficulty and is not due exclusively to the direct effects of a substance (e.g., withdrawal from opioids). ${ }^{6} \mathrm{PE}$ is classified into four groups, namely, lifelong $\mathrm{PE}$, acquired $\mathrm{PE}$, natural variable $\mathrm{PE}$ and premature-like ejaculatory dysfunction. ${ }^{13,14}$ Recent evidence has suggested that the pathophysiology of lifelong PE may be influenced by neurobiological or genetic factors and acquired $P E$ is understood to be influenced either by psychological (sexual performance anxiety and psychological or relationship problem) factors or by organic factors, which are commonly associated with other comorbidities. ${ }^{15} \mathrm{PE}$ has been postulated to cause a negative psychological impact on men and spouses. ${ }^{16}$

The psychological impacts of premature ejaculation (PE), which include guilt, anxiety and distress, have been well established in western countries. In a multicenter and observational study conducted by Patrick et al. in 2005 more subjects in the PE group reported a greater level of distress than non-PE group. ${ }^{17}$ Another study by Lotti $F$ et al. in 2012 found significant association between phobic anxiety and PE. ${ }^{18}$ Moreover, a cohort study of 334 Korean men explored the association between depression and PE. They found that self-assessed PE patients suffered from various psychological problems, such as depression, low 
self- esteem, bother and low sexual satisfaction. ${ }^{19}$ There is no published study on PE in Bangladesh so far. For this reason the objective of this study was to find out the prevalence and associated psycho-social factors of PE among the patients who attended with the complaints of sexual dysfunction. This study will provide baseline information for future analytical and epidemiological studies in this area and will help in promoting awareness and development of standardized methods of PE diagnosis, assessment and treatment.

\section{Materials and methods}

This was a cross-sectional study conducted from August 2017 to June 2018, among the male patients with complaints of PE attending in the Sexual Dysfunction Clinic of National Institute of Mental Health (NIMH), Dhaka, Bangladesh. A total of 290 patients aged 18-60 years were selected by convenient sampling technique. Patients with unstable psychiatric illnesses, mental retardation, and illiteracy were excluded. Informed written consent was taken prior to data collection and all ethical procedures including confidentiality were ensured. For data collection, a semi-structured questionnaire in Bangla prepared by the researchers containing socio-demographic variables was distributed to the patients. The Bangla version of Premature Ejaculation Diagnostic Tool (PEDT) was applied to diagnose premature ejaculation (PE). ${ }^{20}$ The PEDT had a high level of agreement with the clinical diagnosis (according to DSM-IV) and good test-retest reliability with an interclass correlation coefficient of 0.888 . It had 5 items with 5 domains (ejaculatory control, frequency, minimal stimulation, distress and interpersonal difficulty) with 5-Likert Scale (0-4) and the score-range from 0 to 20 . Ascore of < 8 indicates no PE; 9 and 10 indicated probable $\mathrm{PE}$; and $>11$ indicated confirmed PE. In this study, the PE cases included (confirmed and probable cases of PE) using Premature Ejaculation and Diagnostic Tool (PEDT) who were scored $>9 .{ }^{21}$ After diagnosing PE, Bangla version of the Depression Anxiety Stress Scales-21 (DASS-21-BV) ${ }^{22}$ was provided to the patients $(n=290)$ to evaluate presence of depression, anxiety and stress but among them 10 did not respond (i.e. finally 280 patients responded). DASS-21 was a widely used tool to assess the prevalence of depression, anxiety and stress. It has 3 domains, i.e. depression, anxiety and stress, with 7 items in each domain. The experience of each symptom over the past week was rated on a 4-Likert scale ranging from 0 (does not apply to me) to 3 (applies to me most or all the time). The scores for each scale were summed. Depression was defined as score of $10-$ 28 plus; anxiety was defined as a score of 8-20 plus; and stress was defined as a score of 15-34 plus. After proper processing and handling, data were encoded then after thorough cleaning and editing of data, analysis was done by Statistical Package for Social Sciences (SPSS) of windows version 16. Quantitative data were expressed as mean and standard deviation and qualitative data as frequency and percentage. Comparison was done by Chi-square $\left(x^{2}\right)$ test and t-test where applicable. A probability $(p)$ value of $<0.05(p<0.05)$ was considered statistically significant and $p<0.01$ was considered highly significant but $p>0.05$ was taken as not-significant. Findings were presented by frequency tables and graphs.

\section{Results}

A total of 280 respondents out of 290 selected patients responded with a response rate of $96.6 \%$. The prevalence of $\mathrm{PE}$ among the respondents was $74(26.4 \%)$ (Figure 1$)$. In this study, age range of the respondents was from 18 to 60 years with the mean age (+SD) of $38.8(+8.44)$ years. $143(51.1 \%)$ of the respondents were in the age-group of $18-40$ years and rest of them (48.9\%) were in the age group of 41-60 years. Among the respondents with $\mathrm{PE}(\mathrm{n}=74), 44.6 \%$ were in the age group of $18-40$ years and $55.4 \%$ were in the age-group of 41-60 years; whereas among the respondents without PE $(n=206) 53.4 \%$ were in the agegroup of $18-40$ years and $46.6 \%$ were in the age-group of $41-60$ years. Mean age of the respondents with PE $(n=74)$ was 40.62 $(+9.04)$ years and mean age of the respondents without PE $(n=206)$ was 38.6 $(+9.43)$ years. The difference in the mean age of both group was not statistically significant $(p>0.05)$ (Table 1$)$. Among the respondents with PE $(n=74), 53(71.6 \%)$ were from urban areas and $21(28.4 \%)$ were from rural areas; whereas among the respondents without PE $(n=206), 76.2 \%$ were from urban areas and $23.8 \%$ were from rural areas. Regarding the religion (Islam vs Hindu) $85.1 \%$ vs $14.9 \%$ were in the group of having $\mathrm{PE}$ and $98.5 \%$ vs $1.5 \%$ were in the group of without $\mathrm{PE}$. Majority $(52.7 \%)$ of the respondents with PE studied up to graduate and post-graduate level and majority (53.9\%) of the respondents without PE studied up to primary and secondary level. Majority of the respondents with $\mathrm{PE}$ vs without $\mathrm{PE}(74.3 \%$ vs $66.5 \%)$ were employed and rest of them were un-employed. The difference between PE group and without PE group in relation to habitat, religion, education and occupation were not statistically significant ( $p>0.05$ ) (Table 1). Regarding smoking status of the respondents, non-smoker vs active smoker were $40.5 \%$ vs $59.5 \%$ in the PE group and $59.2 \%$ vs $40.8 \%$ in the without PE group, respectively. This difference in smoking status between two groups was statistically significant $(p<0.05)$ (Table 1$)$. Depression, anxiety and stress were present alone and in combination among the respondents $(n=280)$. Depression, anxiety and stress were present among $35.1 \%, 12.2 \%$ and $10.8 \%$ (alone) and $13.5 \%$ (combination) of the respondents with PE ( $n=74)$ and among $7.9 \%, 14.6 \%$ and $14.6 \%$ (alone) and $14.6 \%$ (combination) of the respondents without $P E(n=206)$. This difference in the presence of depression, anxiety and stress between two groups was highly significant $(p<0.001)$ (Table 2$)$.

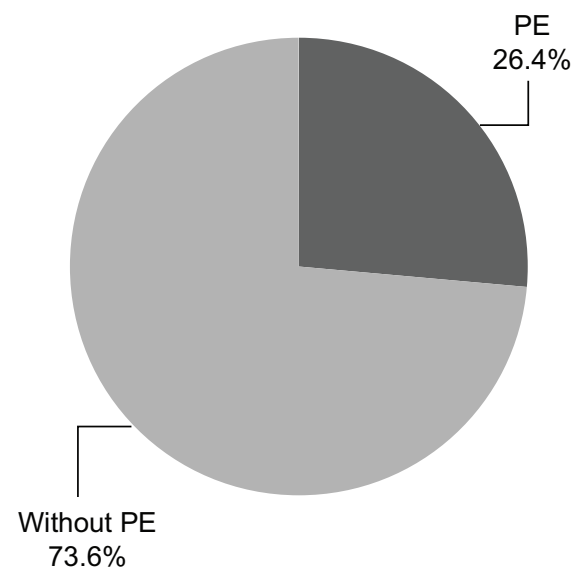

Figure 1: Proportion of PE among the respondents $(n=280)$ 
Psycho-social factors associated with premature ejaculation among the patients attending

Table 1: Socio-demographic characteristics of the respondents $(n=280)$

\begin{tabular}{|c|c|c|c|}
\hline \multirow[t]{2}{*}{ Socio-demographicCharacteristics } & \multicolumn{2}{|c|}{ Presence of PE } & \multirow[t]{2}{*}{${ }^{*} \mathrm{P}$ value } \\
\hline & YesFrequency (\%) & NoFrequency (\%) & \\
\hline \multicolumn{4}{|l|}{ Age group } \\
\hline $18-40$ years & $33(44.6)$ & $110(53.4)$ & ${ }^{* *} .502$ NS \\
\hline $41-60$ years & $41(55.4)$ & $96(46.6)$ & \\
\hline Mean \pm SD & $40.62(+9.04)$ & $38.6(+9.43)$ & \\
\hline \multicolumn{4}{|l|}{ Habitat } \\
\hline Rural & $21(28.4)$ & $49(23.8)$ & $.434^{\mathrm{NS}}$ \\
\hline Urban & $53(71.6)$ & $157(76.2)$ & \\
\hline \multicolumn{4}{|l|}{ Religion } \\
\hline Islam & $63(85.1)$ & $203(98.5)$ & $.000 \mathrm{HS}$ \\
\hline Hindu & $11(14.9)$ & $3(1.5)$ & \\
\hline \multicolumn{4}{|l|}{ Education } \\
\hline Primary and secondary & $35(47.3)$ & $111(53.9)$ & $.331 \mathrm{NS}$ \\
\hline Graduate and post-graduate & $39(52.7)$ & $95(46.1)$ & \\
\hline \multicolumn{4}{|l|}{ Occupation } \\
\hline Employed & $55(74.3)$ & $137(66.5)$ & $.214^{N S}$ \\
\hline Un-employed & $19(25.7)$ & $69(33.5)$ & \\
\hline \multicolumn{4}{|l|}{ Smoking status } \\
\hline Non-smoker & $30(40.5)$ & $122(59.2)$ & $.006^{S}$ \\
\hline Active smoker & $40(69.5)$ & $84(40.8)$ & \\
\hline$\overline{\text { Total }}$ & $74(100)$ & $206(100)$ & \\
\hline
\end{tabular}

a premature ejaculation, ${ }^{*} X^{2}$ (Chi-square) test was done, NS= not significant, $S=$ significant, HS= highly significant. ** Independent sample t-test was done.

Table 2: Psychological co-morbidities and presence of a $\mathrm{PE}(\mathrm{n}=\mathbf{2 8 0})$

\begin{tabular}{lccc}
\hline Co-morbidities & \multicolumn{2}{c}{ Presence of PE } & ${ }^{*} \mathrm{P}$ value \\
\cline { 2 - 3 } & YesFrequency $(\%)$ & NoFrequency $(\%)$ & .000 HS \\
Depression & $26(35.1)$ & $15(7.9)$ & $30(14.6)$ \\
Anxiety & $9(12.2)$ & $30(14.6)$ & $30(14.6)$ \\
Stress & $8(10.8)$ & $101(49.1)$ & \\
D+A+S & $10(13.5)$ & $206(100)$ & \\
Absent & $21(28.2)$ & $74(100)$ &
\end{tabular}

\section{Discussion}

In this study, the PE cases included (confirmed and probable cases of PE) based on a Premature Ejaculation and Diagnostic Tool (PEDT) score of $>9$ and proportion of premature ejaculation was found $26.4 \%$ (74 out of 280 men), which was consistent with previously reported majority of the study findings. ${ }^{7-12}$ Due to the unavailability of published data on premature ejaculation in Bangladesh, results could not be compared in Bangladesh context. In Malaysia, studies have reported prevalence of PE of $29.0 \%$ and $49.1 \%{ }^{23,24}$ First one is almost consistent with this study findings and the later study, which applied a similar methodology, a PEDT questionnaire, an operational definition, and was conducted in a clinical setting, but involved diverse ethnic groups, showed a much higher prevalence. Variations in culture and religion may contribute to this difference.

In the present study, $51.1 \%$ of the respondents were in age group of $18-40$ years and $48.9 \%$ of them were in age group of 41-60 years. Majority (55.4\%) of the respondents with $P E(n=74)$ were in the age-group of $41-60$ years and majority $(53.5 \%)$ of the respondents without PE $(n=206)$ were in the age-group of 
18-40 years. But, the difference in the mean age of both groupwas not statistically significant $(p<0.05)$. In a study of the Italian Society of Andrology with a sample of 12,558 men attending the Andrology Prevention Week 2001, it was shown that men with PE were younger than those without. ${ }^{25}$ Data from the 2004 survey of more than 11,500 men in the United States, Germany and Italy showed that the prevalence of self-reported PE was constant across age groups ranging from 18 to 70 years. ${ }^{26}$ So, the present study findings were not consistent with other study findings. This difference may be explained by the difference in the study population, sample size, study place and study tools.

In this study, $71.6 \%$ of the respondents with PE were from urban areas, $28.4 \%$ were from rural areas. Whereas $76.2 \%$ of the respondents without PE was from urban areas and $23.8 \%$ from rural areas. Regarding the religion (Islam vs Hindu), $85.1 \%$ vs $14.9 \%$ were in the group of having $P E$ and $98.5 \%$ vs $1.5 \%$ were in the group of without PE. Association of PE with habitat was not statistically significant $(p>0.05)$ but association of religion was highly significant $(p<0.001)$ in this study. Data regarding the association between habitat and religion with $\mathrm{PE}$ is scarce. So, more study is needed regarding these issues. In a study by Basile Fasolo C et al. (2005) it was found that men who were more educated had a slightly increased risk. It was also found that stress related to socioeconomic status also increase the risk for PE. ${ }^{25}$ In the present study, majority $74(52.7 \%)$ of the respondents with $\mathrm{PE}$ studied up to graduate and post-graduate level and majority 206(53.9\%) of the respondents without PE studied up to primary and secondary level. Majority of the respondents with PE vs without PE (74.3\% vs $66.5 \%)$ were employed and rest of them were unemployed. The difference between with PE group and without PE group in relation to education and occupation were not statistically significant. So, regarding education and occupation, the findings of this study were in line but didn't fully match with the findings of other studies. In a study conducted among 1230 healthy Turkish men aged 24-30 years, applying PEDT scale to diagnose PE, showed no association between PE prevalence and smoking status. ${ }^{27}$ But, in the present study, non-smoker vs active smoker were $40.5 \%$ vs $59.5 \%$ in the PE group and $59.2 \%$ vs $40.8 \%$ in the without PE group, respectively and the difference in smoking status between two groups was statistically significant $(p<$ 0.05).

The relationship between depression, anxiety and stress with PE might be bi-directional. Depression, anxiety and stress may impair male sexual function and couple's sexual relationships. On the other hand, the poor sexual functioning and satisfaction can produce feelings of frustration and anxiety between partners. Several studies have shown significant association with negative psychological disorders (i.e. depression, anxiety
\& stress) with PE. ${ }^{17-19}$ In the present study, depression, anxiety and stress were present alone and in combination among the respondents. Depression, anxiety and stress were present among $35.13 \%, 12.16 \%$ and $10.81 \%$ (alone) and $13.51 \%$ (combination) of the respondents with PE ( $n=74)$ and among $7.28 \%, 14.56 \%$ and $14.56 \%$ (alone) and $14.56 \%$ (combination) of the respondents without PE $(n=206)$. This difference of presence of depression, anxiety and stress between the two groups (with PE group vs without PE group) was highly significant $(p<0.001)$. So, the findings of the present study regarding psychological factors (depression, anxiety and stress) were consistent with the findings of the previous studies.

Though optimum care had been taken by the researchers, still there were some limitations. PE was diagnosed by applying the Bangla version of PEDT which was based on DSM-IV criteria, though there's existing DSM- 5 citeria for PE. Convenient Sampling Technique was followed in this study, so there could be some selection bias. The study was conducted in one selected institution with relatively small sample size. So, the study population may not represent all the PE patients of Bangladesh and limits the generalization of the results. Moreover, in this study, patients with unstable psychiatric illnesses, mental retardation, illiteracy were excluded. But, in these groups of patients there might have some PE patients. So, there was a probability of underestimation of PE prevalence. In this study, only psychological co-morbidities were seen. But, other clinical co-morbidities like hyperthyroidism, diabetes mellitus, hypertension, chronic prostatitis and erectile dysfunction also play major role in pathophysiology of premature ejaculation. So, much attention needed regarding investigation in these areas.

\section{Conclusion}

In this study, proportion of premature ejaculation was high and religion, smoking status, psychological co-morbidities (depression, anxiety and stress) were significantly associated with PE. So, for better outcome, during assessment psychological factors should be identified properly and psychotherapy should be emphasized along with pharmacotherapy during management of PE patients.

\section{References}

1. Carson CC, Glasser DB, Laumann EO, West SL, Rosen RC. Prevalence and correlates of premature ejaculation among men aged 40 years and older: A United States nationwide population-based study. J Urol 2003;169(4):321.

2. Rosen RC. Prevalence and risk factors of sexual dysfunction in men and women. Curr Psychiatry Rep 2002;2:189-95.

3. Moreia Jr ED. Help-seeking behavior for sexual problems: the Global Study of Sexual Attitudes and Behaviours. Int Clin Pract 2005;59:6.

4. American Psychiatric Association. Diagnostic and Statistical Manual of Mental Disorders, $3^{\text {rd }}$ ed (Text Revision). Washington, DC: American Psychiatric Association; 1980. 
5. World Health Organization. International Classification of Diseases and Related Health Problems, $10^{\text {th }}$ ed. Geneva: World Health Organization; 1994.

6. American Psychiatric Association. Diagnostic and Statistical Manual of Mental Disorders, $4^{\text {th }}$ ed (Text Revision). Washington, DC: American Psychiatric Association; 2000.

7. Porst H, Montorsi F, Rosen RC, Gaynor L, Grupe S, Alexander $J$. The Premature Ejaculation Prevalence and Attitudes (PEPA) survey: prevalence, co-morbidities and professional help-seeking. Eur Urol 2007;51(3 ):816-24.

8. Adaikan PG, Lim P, Ng KK, Fock EL. Asian perspective: premature ejaculation prevalence and attitudes (PEPA) among Singaporean men. J Men's Health 2011;8(S1 ):8846.

9. Park HJ, Park JK, Park K, Lee SW, Kim SW, Yang DY, et al. Prevalence of premature ejaculation in young and middleaged men in Korea: a multicenter internet-based survey from the Korean Andrological Society. Asian J Androl 2010;12( 6):880-9.

10. Silangcruz JMA, Chua ME, Morales ML. Prevalence and factor association of premature ejaculation among adult Asian males with lower urinary tract symptoms. Prostate Int 2015;3(2):65-9.

11. Quek KF, Sallam AA, $\mathrm{Ng} \mathrm{CH}$, Chua CB. Prevalence of sexual problems and its association with social, psychological and physical factors among men in a Malaysian Population: a cross-sectional study. J Sex Med 2008;5(1):70-6.

12. Gao J, Xu C, Liang C, Su P, Peng Z, Shi K, et al. Relationships between intra-vaginal ejaculatory latency time and National Institutes of Health-Chronic Prostatitis Symptom Index in the four types of premature ejaculation syndromes: a large observational study in China. J Sex Med 2014;11(12):3093-101.

13. Serefoglu EC, McMahon CG, Waldinger MD, Althof SE, Shindel A, Adaikan G, et al. An evidence-based unified definition of lifelong and acquired premature ejaculation: report of the second International Society for Sexual Medicine ad hoc committee for the definition of premature ejaculation. Sex Med 2014;2:41-59.

14. Waldinger MD. Recent advances in the classification, neurobiology and treatment of premature ejaculation. Adv Psychosom Med 2008;29:50-69.

15. Serefoglu EC, Yaman O, Cayan S, Asci R, Orhan I, Usta MF, et al. Prevalence of the complaint of ejaculating prematurely and the four premature ejaculation syndromes: results from the Turkish society of andrology sexual health survey. J Sex Med 2011;8(2):540-8.
16. Corona G, Petrone L, Mannucci E, Jannini EA, Mansani R, Magini A, et al. Psycho-biological correlates of rapid ejaculation in patients attending an andrologic unit for sexual dysfunctions. Eur Urol 2004;46(5):615-22.

17. Patrick DL, Althof SE, Pryor JL, Rosen R, Rowland R, Ho KF, et al. Premature ejaculation: an observational study of men and their partners. J Sex Med 2005;2:358-67.

18. Lotti F, Corona G, Rastrelli G, Forti G, Jannini EA, Maggi M. Clinical correlates of erectile dysfunction and premature ejaculation in men with couple infertility. J Sex Med 2012;9(10):2698-2707.

19. Son H, Song SH, Lee JY, Paick JS. Relationship between premature ejaculation and depression in Korean males. J Sex Med 2011;8:2062-70.

20. Islam T. Translation of PEDT into Bangla and validation among Bengali speaking male patients attending in the psychiatric out-patient department (OPD), BSMMU (MD thesis). Dhaka: Bangabandhu Sheikh Mujib Medical University;2017.

21. Symonds T, Perelman MA, Althof S, Giuliano F, Martin M, May K, et al. Development and validation of a premature ejaculation diagnostic tool. Eur Urol 2007;52(2):565-73.

22. Alim SMAHM, Kibria SME, Islam MJ, Uddin MZ, Nessa M, Wahab MA, et al. Translation of DASS 21 into Bangla and validation among medical students. Bang J Psychiatry 2014;28(2):67-70.

23. Tang ws, Khoo EM. Prevalence and correlates of premature ejaculation in a primary care setting: a preliminary crosssectional study. J Sex Med 2011;8(7):2071-8.

24. McMahon CG, Lee G, Park JK, Adaikan PG. Premature ejaculation and erectile dysfunction prevalence and attitudes in the Asia-Pacific region. J Sex Med 2012;9(2):454-65.

25. Basile Fasolo C, Mirone V, Gentile V, Parazzini F, Ricci E. Premature ejaculation: prevalence and associated conditions in a sample of 12,558 men attending the andrology prevention week 2001-a study of the Italian Society of Andrology (SIA). J Sex Med 2005;2(3):376-82.

26. Porst $\mathrm{H}$. Factors related to seeking treatment for premature ejaculation: results from the Premature Ejaculation Prevalence and Attitudes (PEPA) Survey. Presented at $7^{\text {th }}$ Congress of the European Society for Sexual Medicine, London, United Kingdom, December 5-8,2004.

27. Karabakan M, Bozcurt A, Hirik E, Celebi B. The prevalence of premature ejaculation in young Turkish men. Andrologia 2016;24:1-5. 